\title{
Article \\ Pool Boiling Heat Transfer Performance and Bubble Dynamics from Pin Fin-Modified Surfaces with Geometrical Shape Variation
}

\author{
Indro Pranoto *(D), Muhammad Aulia Rahman (D) and Pradhana A. P. Mahardhika
}

check for updates

Citation: Pranoto, I.; Rahman, M.A.; Mahardhika, P.A.P. Pool Boiling Heat Transfer Performance and Bubble Dynamics from Pin Fin-Modified Surfaces with Geometrical Shape Variation. Energies 2022, 15, 1847. https://doi.org/10.3390/en15051847 Academic Editor: Patrick Phelan

Received: 17 January 2022 Accepted: 25 February 2022 Published: 2 March 2022

Publisher's Note: MDPI stays neutral with regard to jurisdictional claims in published maps and institutional affiliations.

Copyright: (C) 2022 by the authors. Licensee MDPI, Basel, Switzerland. This article is an open access article distributed under the terms and conditions of the Creative Commons Attribution (CC BY) license (https:// creativecommons.org/licenses/by/ $4.0 /)$.
Department of Mechanical and Industrial Engineering, Faculty of Engineering, Gadjah Mada University, Jl. Grafika No. 2 Kampus UGM, Yogyakarta 55281, Indonesia; muhammadaulia@mail.ugm.ac.id (M.A.R.); pradhana.adhi.p.m@mail.ugm.ac.id (P.A.P.M.)

* Correspondence: indro.pranoto@ugm.ac.id

\begin{abstract}
In this paper, an experimental study investigating the effect of the geometrical shape of the circular and rectangular pin fins on the heat transfer performance and the boiling phenomenon is presented. A pool boiling experiment in the HFE-7100 dielectric working fluid under atmospheric pressure was conducted. Boiling curves and boiling heat transfer coefficients of different test cases were plotted to evaluate the heat transfer performance as well as the captured images of the boiling phenomenon on the test samples. Two quantities, flow resistance and wetted perimeter, were calculated to understand the behaviour of the boiling physics due to variation of fin geometrical shape and, hence, their effect on the heat transfer performance. It was found that the cooling performance of the rectangular pin fins was higher than that of the circular pin fins, despite having a slightly higher flow resistance of $4 \%$ and $7 \%$, respectively. This is believed to be the result of the longer wetted perimeter up to $27 \%$, whereby the nucleation site has a higher probability of generating more bubbles in the same boiling surface area. For the tested modified boiling surface with 196 and 144 pin fins, the average heat transfer performances were found to have differences of up to 3.54 and 1.58 times larger, respectively.
\end{abstract}

Keywords: pool boiling; bubble dynamics; modified surface; pin fin; heat transfer performance; macro structure; electronic cooling; two-phase cooling

\section{Introduction}

Boiling heat transfer has been demonstrated to be an effective cooling mechanism. It provides an excellent heat transfer coefficient due to the chaotic movement of the bubble. In addition to the natural convection of the single-phase liquid, the cooling process is enhanced by the process of bubble evaporation and surface rewetting, which results in a higher heat transfer coefficient [1]. Recently, the heat transfer coefficient from the boiling system is able to be enhanced up to $2 \mathrm{MW} / \mathrm{m}^{2} \cdot{ }^{\circ} \mathrm{C}$, up to ten times larger than forced convection with dielectric liquids [2].

Several industrial applications rely on boiling heat transfer to achieve high heat flux removal for their applications, for instance, nuclear power plants [3], cryogenic applications [4], and server cooling [5]. In server cooling, high heat removal is utterly vital to keep the performance of the computer by maintaining the junction temperature within the allowable criterion. A temperature increase of $2{ }^{\circ} \mathrm{C}$ reduces the performance by up to $10 \%$ [6].

The heat flux dissipated from the electronic chip increases rapidly due to the trend of producing compact yet high-performance computers, as shown in Figure 1. Although the value is currently within the remit of boiling heat transfer, excessive enhancement is necessary to fulfil the requirement in the future. 


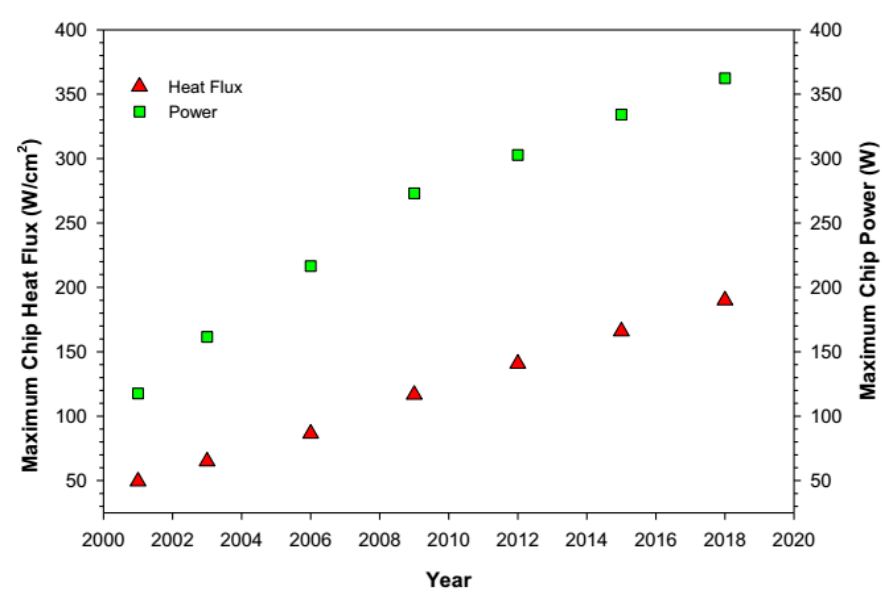

Figure 1. Development of heat flux in electronic devices [7].

Boiling enhancement has been investigated in several studies. Some approaches are employed to increase the heat transfer coefficient of the boiling system, with either a passive or active method [8]. In the passive enhancement, there is no external power necessary for the application, which includes the surface modification $[9,10]$ or cooling fluid enhancement [11,12]. On the other hand, active enhancement requires external power to agitate the process of boiling, for instance, employing electricity [13].

One of the prevailing surface modifications is the application of a macro-structure fin to the heated surface. This approach allows for the considerable increase in heat transfer area by employing an extended surface occupying a limited base area. Despite the advancement of micro-fabrication technology, which provides larger area enhancement, macro-fin surfaces offer better robustness in resisting aging, clogging, and oxidation [5].

The main challenge of finned surface modification is formulating the configuration of the fin. Numerous studies have been conducted to yield a better understanding of the effect of some configuration parameters. Rainey and You [14] reported the effect of pin fin height on the heat transfer enhancement. With the fin wide and spacing of $1 \mathrm{~mm}$, it was demonstrated that the heat transfer was significantly improved as the height increased. However, the enhancement was limited when the height exceeded $5 \mathrm{~mm}$. This reduction in fin "effectiveness" is caused by the lower tip temperature at the longer tip, which restricts the surface to generate a bubble. A similar trend was also reported by Parker and ElGenk [15]. Furthermore, the study also illustrated that the bubble residence time, which shows the time of the bubble before detachment, increases in comparison to the plain surface. This is due to the resistance of the flow accumulating between the fins, hence reducing the heat transfer coefficient at the higher heat flux region.

Kelin and Westwater [16] investigated the effect of fin horizontal configuration on the heat transfer performance. It was shown that the effect of spacing was undermined as the distance increased more than $1.575 \mathrm{~mm}$. At this configuration, each fin performed independently, reducing the interaction between the fins. This spacing distance was claimed to be close to the bubble break-off diameter.

Additionally, more comprehensive studies exploring the effect of bubble dynamics have been carried out on the micro-structured surface. For instance, Zhang et al. [17] investigated the effect of the micro pin fin gap by introducing capillary resistance. It was found that the flow resistance due to gap and surface tension is responsible for altering the movement of the bubble during the rewetting process.

Recently, the effect of pin fin geometrical configuration has been widely investigated, albeit the exact sizing varies based on many parameters. Numerous studies have addressed the effect of geometrical shape in natural convection, for instance in porous media $[18,19]$ or on micro-structured surfaces. However, so far, little work has been carried out comparing the effect of macro pin fin geometrical shape on the pool boiling heat transfer performance, especially in the dielectric fluid. This study aims to compare the boiling heat transfer perfor- 
mance between circular and rectangular macro pin fins. Two sets of modified surfaces with the fin gap of $1 \mathrm{~mm}$ and $1.5 \mathrm{~mm}$ were investigated in a pool boiling experimental chamber. For each simulation set, the heat transfer performances for circular and rectangular pin fins were compared.

\section{Experiment}

\subsection{Experimental Facility}

In this study, the experiment was performed in a pool boiling experimental facility, as shown in Figure 2. It contains mainly the heating base, boiling chamber, and condenser.

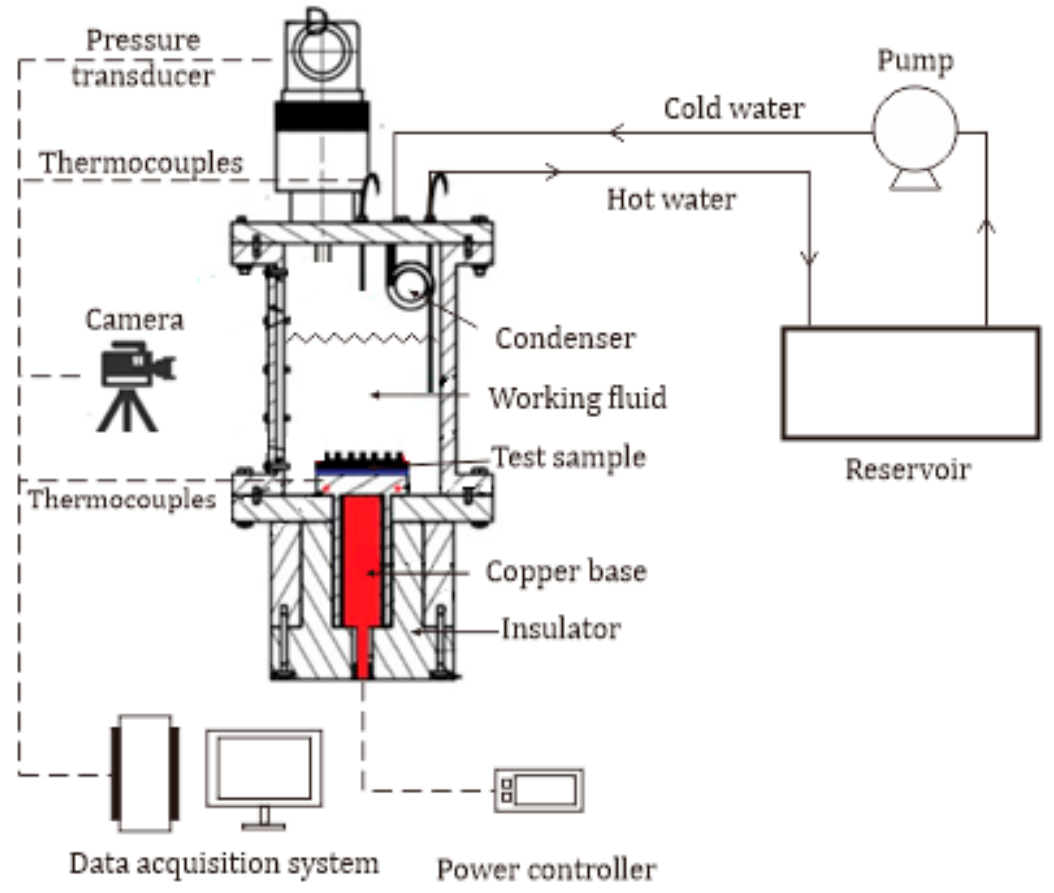

Figure 2. Schematic diagram of the experimental facility.

The heating base is designed to represent the heat flux from an electronic device. The overall dimensions of the heating base assembly are $100 \mathrm{~mm}(l) \times 100 \mathrm{~mm}(w) \times 50 \mathrm{~mm}$ (h). A cartridge heater with the maximum power of $300 \mathrm{~W}$ is attached at the centre of the copper base to transmit the heat onto the heated surface, whereby the test sample with the dimensions of $30 \mathrm{~mm} \times 30 \mathrm{~mm}$ is attached. A power control unit is employed to control and monitor the total amount of power going into the heater. To restrict the heat loss to the surrounding, the heater is insulated by a thick Teflon base on its circumference. A couple of $k$-type thermocouples are installed to measure the temperature at two different locations.

The boiling chamber is made of aluminium with a total volume of $5.492 \times 10^{5} \mathrm{~mm}^{3}$. Two transparent windows are installed at the front and rear parts of the chamber to allow the observation and illumination of the boiling process of the test sample. Rubber gaskets are inserted in each connection to restrict the liquid leakage during the experiment. Two ktype thermocouples are installed to observe the liquid and vapour temperature. A pressure transducer is employed to validate the working pressure is kept at $1 \mathrm{~atm}$.

At the upper part of the boiling chamber, a water-cooled condenser is incorporated to condensate the vapour generated during the experiment and to maintain the working condition at a steady state. Cold water from a reservoir is pumped through a coil made of copper at such a rate that the heat removed is equal to the heat input from the heater.

\subsection{Test Samples}

Four test samples in this study were fabricated from copper alloy block C106/CW024A with thermal conductivity of $166 \mathrm{~W} / \mathrm{m} \cdot \mathrm{K}$. Two samples are constituted of circular pin fins, 
whilst the two others are constituted of rectangular pin fins, as shown in Figure 3. The surface area and fin width are kept the same at $1516 \mathrm{~mm}^{2}$ and $1 \mathrm{~mm}$, respectively. Other dimensions, for instance, fin gap and height, are adjusted accordingly. A summary of the sample configurations, hydraulic diameter $\left(D_{h}\right)$ and wetted perimeter $(P)$ is presented in Table 1.

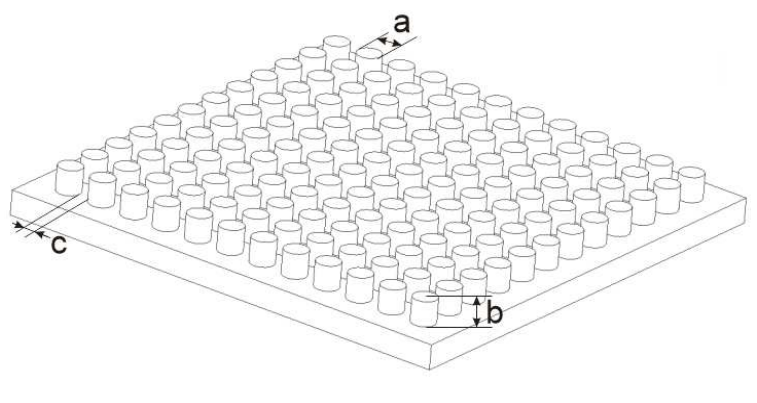

(a)

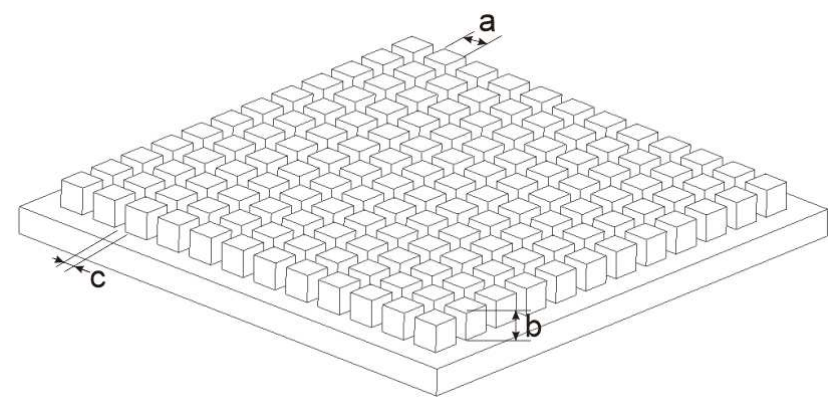

(b)

Figure 3. Sketch and dimensions of the test samples with (a) circular pin fins and (b) rectangular pin fins.

Table 1. Configurations and dimensions of the test samples.

\begin{tabular}{ccccccc}
\hline $\begin{array}{c}\text { Test } \\
\text { Sample }\end{array}$ & Number of Fins & Fin Width $(\boldsymbol{a}), \mathbf{m m}$ & Fin Gap (b), mm & $\begin{array}{c}\text { Fin Height }(\boldsymbol{c}), \\
\mathbf{~ m m}\end{array}$ & $\boldsymbol{D}_{\boldsymbol{h}}, \mathbf{m m}$ & $\boldsymbol{P}, \mathbf{m m}$ \\
\hline C1 & 196 & 1 & 1 & 1 & 4.09 & 3.14 \\
C2 & 196 & 1 & 1.5 & 1.36 & 6.96 & 3.14 \\
S1 & 144 & 1 & 1 & 0.79 & 4 & 5.25 \\
S2 & 144 & 1 & 1.5 & 1.07 & 4 \\
\hline
\end{tabular}

The experiment was conducted in sub-cooled boiling conditions. Dielectric fluid HFE7100 was selected as the working fluid at $1 \mathrm{~atm}$, with the properties provided in Table 2. A dielectric fluid was selected due to its compatibility in the electronic cooling application due to its low boiling point. This allows the electronic devices to undergo two-phase cooling within the accepted temperature criterion. Additionally, the low dielectric strength allows the fluid to be applied in the immersion cooling without causing a short circuit.

Table 2. Properties of HFE-7100 at 1 atm.

\begin{tabular}{cc}
\hline Properties & Values \\
\hline Boiling point $\left({ }^{\circ} \mathrm{C}\right)$ & 61 \\
Vapour pressure $(\mathrm{kPa})$ & 27 \\
Liquid density $\left(\mathrm{kg} / \mathrm{m}^{3}\right)$ & 1520 \\
Specific heat $\left(\mathrm{J} / \mathrm{kg} \cdot{ }^{\circ} \mathrm{C}\right)$ & 1170 \\
Latent heat vaporization $(\mathrm{kJ} / \mathrm{kg})$ & 112 \\
Thermal conductivity $(\mathrm{W} / \mathrm{m} \cdot \mathrm{K})$ & 0.068 \\
Surface tension $(\mathrm{mN} / \mathrm{m})$ & 13.6 \\
Dielectric strength $0.1^{\prime \prime}$ gap $(\mathrm{kV})$ & 40 \\
\hline
\end{tabular}

\subsection{Experimental Procedures and Uncertainty Analysis}

Constant heat flux was incorporated into the experiment. The heat flux was increased gradually from $0.5 \mathrm{~W} / \mathrm{cm}^{2}$ to $3 \mathrm{~W} / \mathrm{cm}^{2}$ in increments of $0.5 \mathrm{~W} / \mathrm{cm}^{2}$ and was maintained in $10 \mathrm{~min}$ to ensure the steady-state, i.e., the temperature variation is negligible. The temperature measured by two thermocouples in the heating base was then recorded in a data logger and visualized in LabView for 20 iterations. Data recorded from thermocouples in the boiling chamber and pressure transducer were monitored for validating the steady 
working condition. Additionally, a macro-lens camera was incorporated to observe the boiling phenomenon in the test sample.

By employing one-dimensional heat conduction and the data recorded from the thermocouples in the heating base, the surface temperature could be calculated through the resistance of $0.9296 \mathrm{~K} / \mathrm{W}$, which results in the local surface temperatures of $T_{S 1}$ and $T_{s 2}$. Finally, the average wall temperature is calculated as follows:

$$
T_{s}=\frac{T_{s 1}+T_{s 2}}{2}
$$

The uncertainty of the thermocouples is measured at $\pm 0.5^{\circ} \mathrm{C}$, while the pressure transducer non-linearity is $0.25-0.5 \%$. The heat loss $\left(q^{\prime \prime}{ }_{\text {loss }}\right)$ of the heating base through the insulation layer was subtracted from the input heat flux $\left(q^{\prime \prime}{ }_{\text {input }}\right)$ measured in the watt meter for the calculation of the neat heat flux $\left(q^{\prime \prime}\right)$. It was measured by installing a set of additional thermocouples between the heating element and the insulation layer. The measured temperature differences were then incorporated to the conduction heat transfer of $q^{\prime \prime}{ }_{\text {loss }}=k A \Delta T / L$. Based on the validation experiment, the heat loss is estimated to be around $8 \%$.

In this study, the uncertainty of the boiling heat transfer coefficient $\left(h_{b}\right)$ is calculated by incorporating Taylor's equation [20]. Assuming that the measured quantities follow Gaussian random distribution, the uncertainty is calculated as follows:

$$
\frac{\delta h_{b}}{h_{b}}=\sqrt{\left(\frac{\delta v}{v}\right)^{2}+\left(\frac{\delta w}{w}\right)^{2}+\ldots+\left(\frac{\delta z}{z}\right)^{2}}
$$

Here, $v, w, \ldots, z$ are independent uncertain parameters that contribute to the determination of $h_{b}$. For $N$, number of samples, i.e., for the independent parameter of $v$, the uncertainty of each parameter is considered from the standard deviation $\left(\sigma_{v}\right)$, which can be obtained by the following:

$$
\sigma_{v}=\sqrt{\frac{1}{N} \sum_{i=1}^{N}\left(v_{i}-\bar{v}\right)^{2}}
$$

In this equation, $v_{i}$ is the measured value and $\bar{v}$ is the mean value for the independent parameter of $v$. Therefore, the uncertainty of $\delta v$ is given by the following:

$$
\delta v=\frac{\sigma_{v}}{\sqrt{N}}
$$

The number of repeated experiments for each variation was set to three $(N=3)$. By ensuring all data were taken in a steady state, the uncertainty obtained for each quantity is minimalized. The value of $h_{b}$ is calculated as the function of $q^{\prime \prime}, T_{s}$, and $T_{\text {sat }}$ (see Equation (5)) with the measured uncertainties of $3.3 \%, 1.5 \%$, and $1.8 \%$, respectively. By incorporating Equation (2), the average uncertainty of $h_{b}$ is estimated to be around $4 \%$. Additionally, systematic uncertainty due to improper procedures and human errors is minimized by careful conduction of the experiment.

\section{Results and Discussion}

\subsection{Boiling Curve and Heat Transfer Performance}

Figures 4 and 5 depict the boiling curve of the modified surface with 196 and 144 fins, respectively. In these graphs, $\Delta T_{e}$ is defined as the difference between the surface temperature and the saturated temperature of the working fluid. All test cases demonstrate a steeper curve at a higher heat flux $\left(>1.5 \mathrm{~W} / \mathrm{cm}^{2}\right)$, whereby the rise in the surface temperature is slower as the heat flux increases. This occurrence is the result of the Onset of Nucleate Boiling (ONB), whereby the generation of the bubble at the heated surface starts 
to be initiated. This indicates the beginning of the boiling process; hence, two additional heat transfer mechanisms from bubble evaporation and surface rewetting start to take effect. Further analysis in this study incorporates the result initiated from this point.

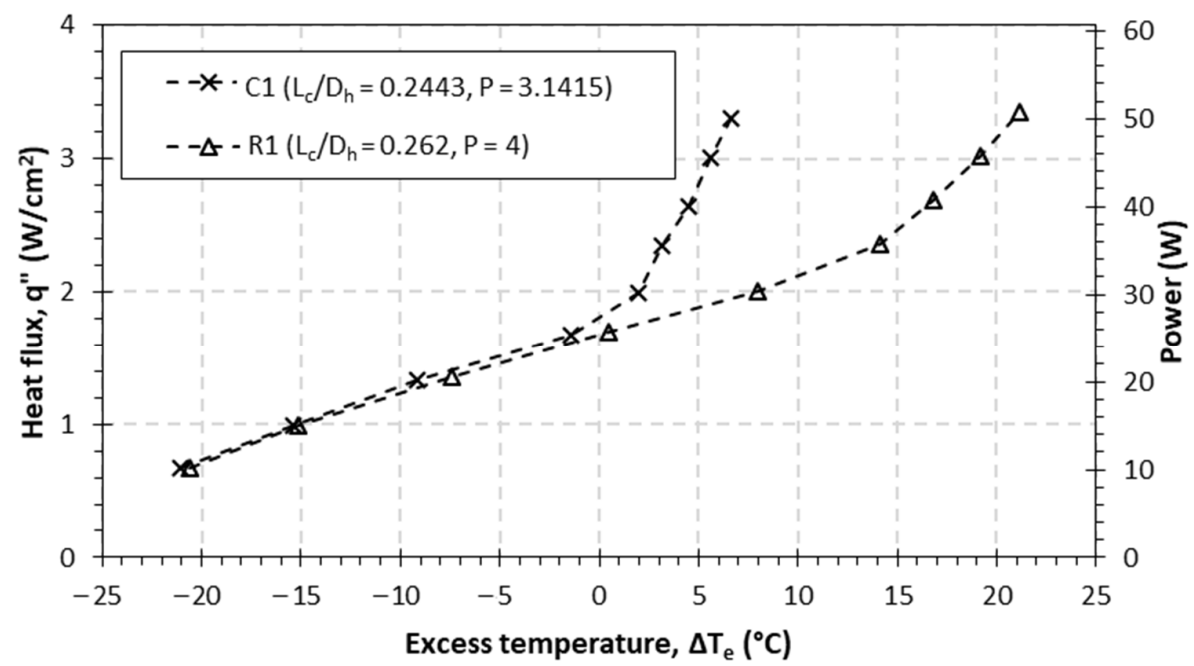

Figure 4. Boiling curve of test case with 196 pin fins.

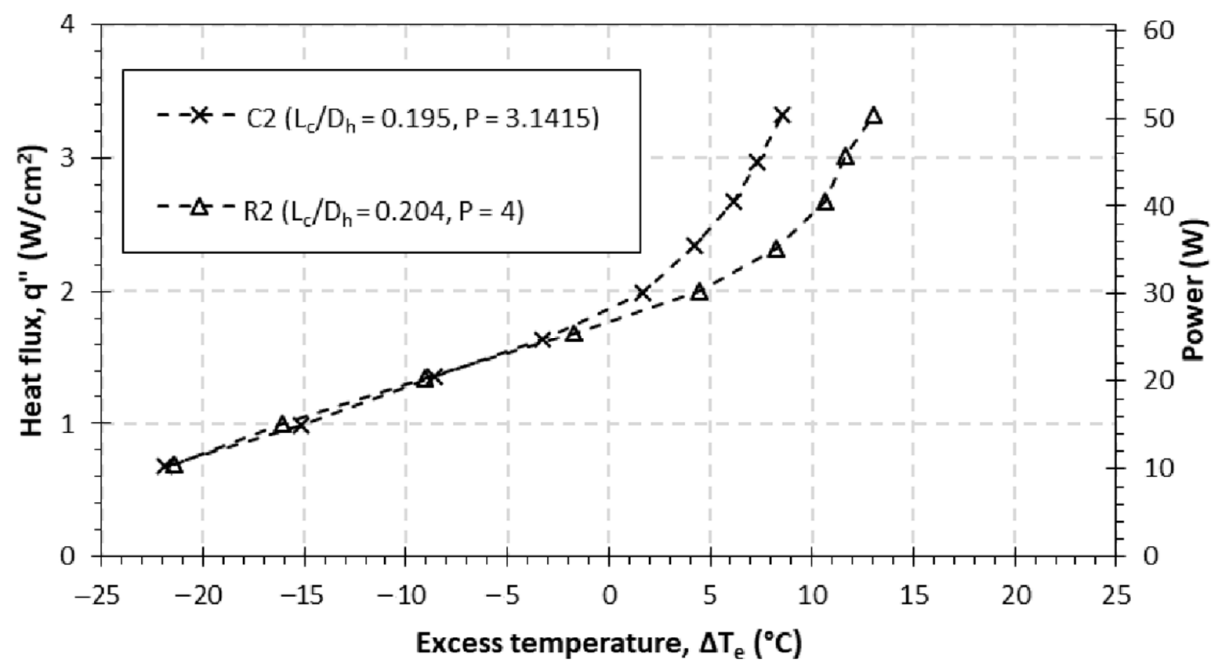

Figure 5. Boiling curve of test case with 144 pin fins.

Among the test samples, configuration R1 has the lowest surface temperature $\left(6.6{ }^{\circ} \mathrm{C}\right)$ at the highest heat flux. This indicates that the surface is able to maintain the maximum temperature within the acceptance criterion of $60{ }^{\circ} \mathrm{C}[6]$ at the power generation of $52 \mathrm{~W}$, which is the typical power of an 8-core CPU [21].

The boiling curves depicted in Figures 5 and 6 demonstrate the enhancement of the cooling performance incorporated to the rectangular pin fin, indicated by a steeper curve. To quantify the enhancement, the boiling heat transfer coefficient is calculated by the following equation:

$$
h_{b}=\frac{q^{\prime \prime}}{\Delta T_{e}}=\frac{q^{\prime \prime}}{\left(T_{s}-T_{s a t}\right)}
$$

By incorporating Equation (5), the boiling heat transfer coefficients for all test cases at high heat flux, where the boiling has been initiated, are plotted in Figures 6 and 7 . Note that $q^{\prime \prime}$ is the net heat flux, which can be obtained by subtracting the input heat flux by the heat loss through the insulation layer. As discussed earlier, all test cases demonstrate that the heat transfer coefficient of the rectangular pin fin is significantly larger than the circular pin fin. Increases of $254 \%$ and $58 \%$ in the average boiling heat transfer coefficients are observed 
for the test cases with 196 and 144 pin fins, respectively. Whilst there is a gradual decrease for the rectangular pin fin as the heat flux rises, the circular pin fin shows a relatively stagnant value for all heat fluxes. This decrease is caused by the larger amount of bubbles generated, which leads to bubble crowding. When the bubble generation is too high, the merit of boiling heat transfer is undermined by the presence of critical heat flux, where the blanket of vapour reduces the heat transfer enhancement caused by bubble movement. This trend is observed for both test cases with 196 and 144 pin fins. Nevertheless, the lowest value obtained from the rectangular test case is still larger than the circular test case. The explanation of this phenomenon is discussed in the following section.

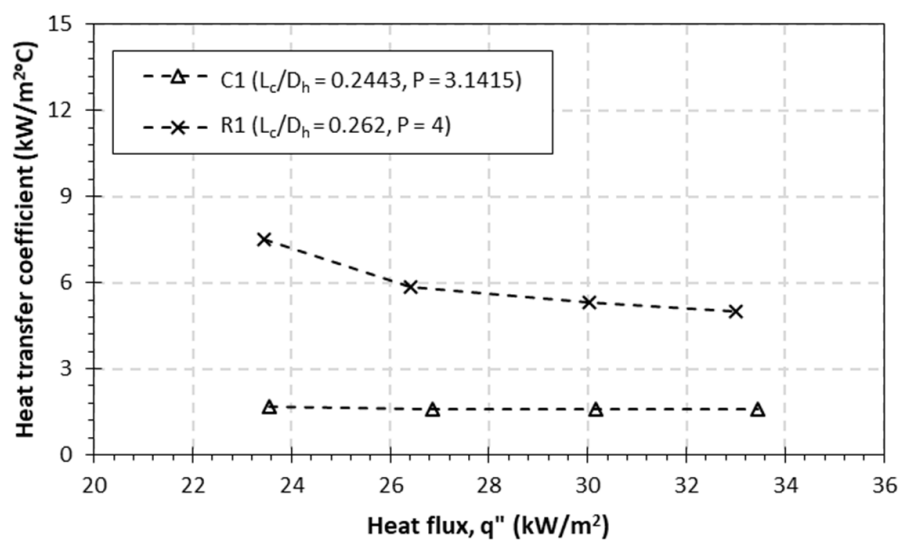

Figure 6. Heat transfer coefficient of the test case with 196 pin fins.

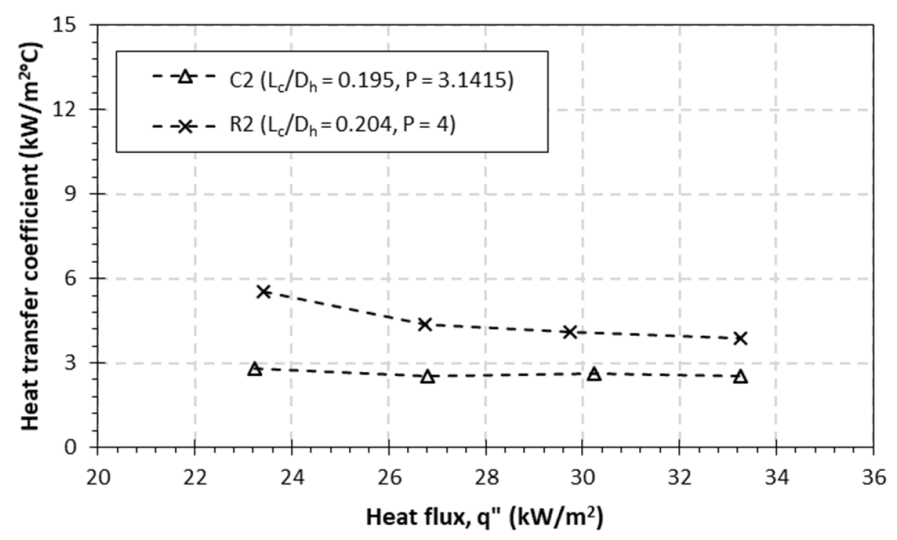

Figure 7. Heat transfer coefficient of the test case with 144 pin fins.

\subsection{Effect of Geometrical Shape}

The physics of the boiling phenomenon has identified the behaviour of two wall boiling parameters: bubble departure frequency $(f)$ and nucleation site density $\left(N_{A}\right)$. Bubble departure frequency defines the number of bubbles that depart from the cavity at a particular time scale. On the other hand, nucleation site density is the number of cavities where the bubble is able to emerge in a specified heating area. Both parameters affect the capacity of the heat transfer due to evaporation $\left(q^{\prime \prime}\right.$ evap $)$ and rewetting $\left(q^{\prime \prime}\right.$ rewet $)$ since both processes occur when the bubble detaches from the cavity. In addition to the natural convection at the area without the effect of boiling, the heat transfer due to these two mechanisms are defined by Kurul and Podowski [1] as follows:

$$
q_{\text {evap }}^{\prime \prime}=\left(\frac{\pi D_{B}^{3}}{6}\right) h_{f g} \rho_{f} N_{A} f
$$




$$
q^{\prime \prime}{ }_{\text {rewet }}=A_{b} \sqrt{\frac{f k_{f} \rho_{f} c_{f}}{\pi}}\left(T_{s}-T_{f}\right)
$$

Here, $D_{B}$ is the bubble departure diameter, $h_{f g}$ is the enthalpy of vaporization, and $A_{b}$ is the boiling area fraction, whereas $k_{f}, \rho_{f}$, and $c_{f}$ are the thermal conductivity, density, and specific heat of the liquid, respectively. From these equations, it is clearly demonstrated that both parameters have major roles in the effectiveness of the boiling process. Hence, comparing both parameters is necessary to understand the behaviour of a boiling process, i.e., a comparison of the geometrical shape of a pin fin.

Recently, there is no unified equation to predict the exact value for both quantities for all working conditions, particularly on the macro-structure pin fin. Hence, a dimensionless number to represent the physics of bubble dynamics is employed. Zhang et al. [16] introduced a capillary resistance number in micro fin to represent the resistance of the flow to occupy the empty space during the rewetting process. In this study, a modification of the capillary resistance is introduced. By adapting the flow resistance in a pipe, the flow resistance in the macro pin fin is calculated by altering the diameter $\left(D_{h}\right)$ and total length $\left(L_{c}\right)$ of the pipe as the hydraulic diameter between the fins arrangement and the height of the fin. Hence, the dimensionless number employed for the analysis can be determined by the following:

$$
\text { macro pin fin flow resistance }=\left(\frac{L_{c}}{D_{h}}\right)=\frac{c}{(4 A / P)}
$$

In this equation, $c$ is the height of the fin (see Figure 3), $A$ and $P$ are flow area and wetted perimeter within the fins arrangement, respectively.

This dimensionless number represents the resistance of the bubble to move into bulk fluid after detachment from the cavity. As the movement of the bubble detached is restricted by the larger pressure drop due to flow resistance, the frequency of the bubble reduces accordingly. This approach is consistent with the results from several existing studies, for instance, Klein and Westwater [16], which proved that the heat transfer is enhanced when the fin gap is larger. However, this contradicts the results shown in Figures 7 and 8, whereby the heat transfer coefficient of the rectangular pin fin is larger despite having slightly lower flow resistance.

Further analysis is conducted by determining the behaviour of the nucleation site density in the modified surface. This parameter is very difficult to predict due to its dependency on the actual surface condition [22]. For the plain surface, it is practically calculated as the function of local wall superheat, whilst the cavity density is assumed to be random with a calibration constant depending on the microstructure, i.e., surface roughness. In the modified surface, however, the assumption of the cavity site cannot be treated as such. Despite having the same microstructure, the length of the 'sharp corner' in the rectangular pin fin is much larger than in the circular pin fin. In this location, the cavity site tends to appear at a higher probability due to the natural defect of the material [22]. This leads to a higher probability of the occurrence at the cavity site, hence increasing the nucleation site density. This phenomenon is observed during the experiment, where the bubble that appears on the rectangular test case is larger than in the circular test case at the same heat flux. Some examples of the comparison are observed by a macro-lens camera, as presented in Figure 8. 


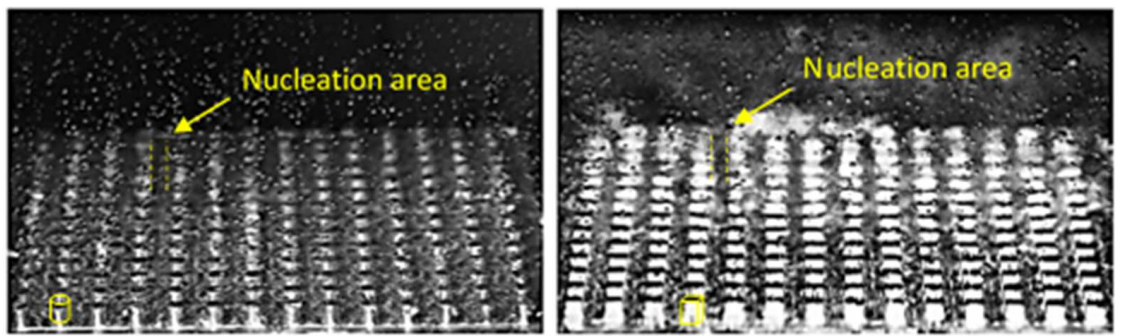

(a)

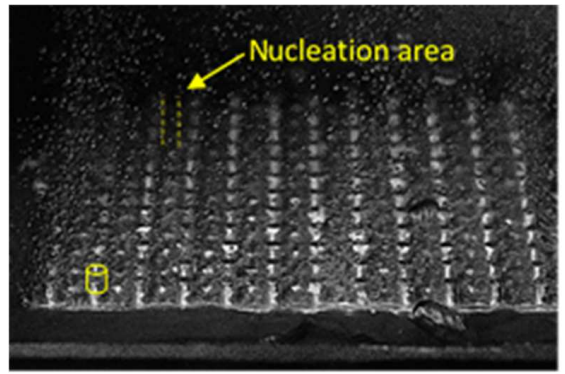

(c) (b)

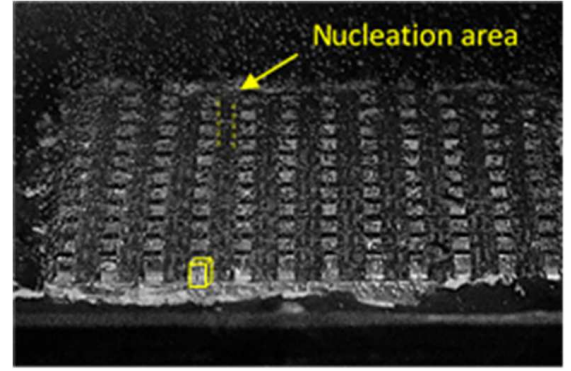

(d)

Figure 8. Macro image of the boiling phenomenon from: (a) $\mathrm{C} 1$ at $q^{\prime \prime}=20 \mathrm{~kW} / \mathrm{m}^{2}$; (b) R1 at $q^{\prime \prime}=20 \mathrm{~kW} / \mathrm{m}^{2} ;$ (c) C2 at $q^{\prime \prime}=35 \mathrm{~kW} / \mathrm{m}^{2} ;$ (d) R2 at $q^{\prime \prime}=35 \mathrm{~kW} / \mathrm{m}^{2}$.

The total length of the 'sharp corner' in the specified area is the same as wetted perimeter $(P)$ in the calculation of hydraulic diameter, as compared in Figure 9. Although the cavity number cannot be quantified straightforward due to the undetermined distribution of natural defects at the sharp corner, the probability of having more cavity sites is higher as the wetted perimeter increases. This explains the higher boiling heat transfer coefficient observed at the rectangular test cases despite having higher flow resistance. The effect of the slight reduction in the frequency is undermined by significant enhancement in the nucleation site density, hence better cooling performance. The comparison is summed up in Table 3.

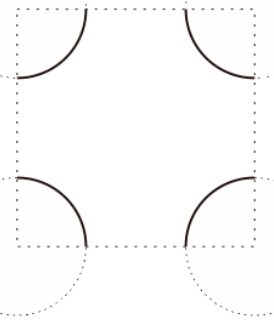

(a)

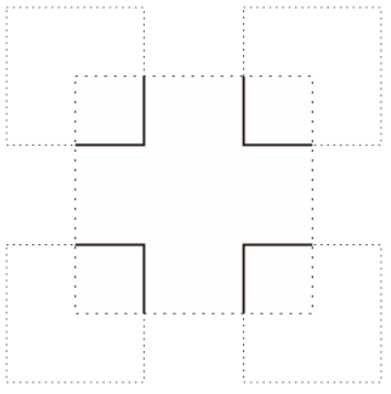

(b)

Figure 9. Comparison and illustration of wetted perimeter: (a) circular pin fins and (b) rectangular pin fins.

Table 3. Summary of the heat transfer performance comparison.

\begin{tabular}{cccc}
\hline Number of Fin & $\frac{\left(L_{c} / D_{h}\right)_{r e c}}{\left(L_{c} / D_{h}\right)_{c i r}}$ & $\frac{P_{r e c}}{P_{c i r}}$ & $\frac{\bar{h}_{r e c}}{\bar{h}_{c i r}}$ \\
\hline 196 & 1.07 & 1.27 & 3.54 \\
144 & 1.04 & 1.27 & 1.58 \\
\hline
\end{tabular}

\section{Conclusions}

In this study, the effect of the geometrical shape of rectangular and circular pin fins on boiling performance of the modified surface was investigated. A set of pool boiling 
experiments employing HFE-7100 as the working fluid under atmospheric pressure was conducted to compare the boiling curve and heat transfer coefficient of the selected modified surface. Some key findings from the study are presented as follows:

1. The boiling performances of the rectangular and circular pin fins are enhanced after $\mathrm{ONB}$, which is the result of the agitated movement by evaporation and rewetting process during the bubble detachment. On this regime, an increase in the same increment in heat flux results in a smaller increase in the surface temperature.

2. The heat transfer performance of the rectangular pin fin is better than that of the circular pin, which has an average value of $5.95 \mathrm{~kW} / \mathrm{m}^{2} \cdot{ }^{\circ} \mathrm{C}$ and $4.49 \mathrm{~kW} / \mathrm{m}^{2} .{ }^{\circ} \mathrm{C}$ for the test case with 196 and 144 pin fins, respectively. Meanwhile, the circular test cases only show the average value of $1.68 \mathrm{~kW} / \mathrm{m}^{2} .{ }^{\circ} \mathrm{C}$ and $2.84 \mathrm{~kW} / \mathrm{m}^{2} \cdot{ }^{\circ} \mathrm{C}$. On average, the heat transfer performance of the rectangular pin fin is 2.54 times higher than the circular pin fin.

3. The flow resistance, due to the fin arrangement, of the rectangular pin fin is slightly higher (around 1.06 times), resulting in the lower bubble departure frequency. However, the nucleation site has a larger probability of a cavity site due to the longer wetted perimeter in the same area, up to 1.27 times longer. This leads to an increase in the overall heat transfer performance despite having a lower bubble departure frequency.

Author Contributions: Conceptualization, I.P.; methodology, I.P.; formal analysis, I.P. and M.A.R.; validation, M.A.R. and P.A.P.M.; result analysis, I.P. and M.A.R.; investigation, M.A.R. and P.A.P.M.; writing—original draft preparation, M.A.R.; writing—review and editing, I.P.; visualization, P.A.P.M.; supervision, I.P.; funding acquisition, I.P. All authors have read and agreed to the published version of the manuscript.

Funding: This research received no external funding.

Conflicts of Interest: The authors declare no conflict of interest. The funders had no role in the design of the study; in the collection, analyses, or interpretation of data; in the writing of the manuscript; or in the decision to publish the results.

\section{Nomenclature}

$a \quad$ Fin width (mm)

$A_{b} \quad$ Boiling area fraction (dimensionless)

$b \quad$ Fin gap (mm)

c Fin height (mm)

$c_{f} \quad$ Specific heat of the liquid $\left(\mathrm{kJ} / \mathrm{kg}^{\circ} \cdot \mathrm{C}\right)$

$D_{B} \quad$ Bubble departure diameter $(\mathrm{mm})$

$D_{h} \quad$ Hydraulic diameter $(\mathrm{mm})$

$f \quad$ Bubble departure frequency $(\mathrm{Hz})$

$h_{b} \quad$ Boiling heat transfer coefficient $\left(\mathrm{kW} / \mathrm{m}^{2} \cdot{ }^{\circ} \mathrm{C}\right)$

$\overline{h_{b}} \quad$ Average boiling heat transfer coefficient $\left(\mathrm{kW} / \mathrm{m}^{2} \cdot{ }^{\circ} \mathrm{C}\right)$

$h_{f g} \quad$ Enthalpy of vaporization $(\mathrm{kJ} / \mathrm{kg})$

$k_{f} \quad$ Thermal conductivity of the fluid $\left(\mathrm{W} / \mathrm{m}^{\circ} \cdot \mathrm{C}\right)$

$L_{c} \quad$ Characteristic length $(\mathrm{mm})$

$P \quad$ Wetted perimeter (m)

$q^{\prime \prime} \quad$ Net heat flux $=q^{\prime \prime}{ }_{\text {input }}-q^{\prime \prime}{ }_{\text {loss }}\left(\mathrm{W} / \mathrm{m}^{2}\right)$

$q_{\text {evap }}^{\prime \prime}$ Evaporation heat flux $\left(\mathrm{W} / \mathrm{m}^{2}\right)$

$q^{\prime \prime}{ }_{\text {input }}$ Heat input of cartridge heater $\left(\mathrm{W} / \mathrm{m}^{2}\right)$

$q^{\prime \prime}$ loss Heat loss through the heating base wall $\left(\mathrm{W} / \mathrm{m}^{2}\right)$

$q^{\prime \prime}$ rewet Rewetting heat flux $\left(\mathrm{W} / \mathrm{m}^{2}\right)$

$T_{S} \quad$ Surface temperature $\left({ }^{\circ} \mathrm{C}\right)$

$\rho_{f} \quad$ Density of the liquid $\left(\mathrm{kg} / \mathrm{m}^{3}\right)$ 


\section{References}

1. Kurul, N.; Podowski, M.Z. Multidimensional effects in forced convection subcooled boiling. In International Heat Transfer Conference Digital Library; Begel House Inc.: Danbury, CT, USA, 1990.

2. El-Genk, M.S. Nucleate boiling enhancements on porous graphite and microporous and macro-Finned copper surfaces nucleate boiling enhancements on porous graphite and microporous and macro-Finned copper surfaces. Heat Transfer. Eng. 2012, 33, 175-204. [CrossRef]

3. Giustini, G. Modelling of boiling flows for nuclear thermal hydraulics applications-A brief review. Invention $2020,5,47$. [CrossRef]

4. Chung, S.; Seo, Y.; Jeon, G.; Kim, J.; Park, J. Parameter study of boiling model for CFD simulation of multiphase-thermal flow in a pipe. J. Ocean. Eng. Technol. 2020, 35, 50-58. [CrossRef]

5. Liang, G.; Mudawar, I. Review of pool boiling enhancement by surface modification. Int. J. Heat Mass Transf. 2021, 128, 892-933. [CrossRef]

6. Kraus, A.D.; Bar-Cohen, A. Thermal Analysis and Control of Electronic Equipment; Hemisphere Publishing Corporation: Washington, DC, USA, 1983.

7. Murshed, S.M.S.; Castro, C.A.N. A critical review of traditional and emerging techniques and fluids for electronics cooling. Renew. Sustain. Energy Rev. 2017, 78, 821-833. [CrossRef]

8. $\quad$ Bergles, A.E.; Webb, R.L.; Junkhan, G.H.; Jensen, M.K. Bibliography on augmentation of convective heat and mass transfer. In Heat Transfer Laboratory Report HTL-19; Iowa State University: Ames, IA, USA, 1979.

9. Pranoto, I.; Leong, K.C. An experimental study of flow boiling heat transfer from porous foam structures in a channel. Appl. Therm. Eng. 2014, 70, 100-114. [CrossRef]

10. Pranoto, I.; Leong, K.C.; Rofiq, A.A.; Arroisi, H.M.; Rahman, M.A. Study on the pool boiling bubble departure diameter and frequency from porous graphite foam structures. In Advances in Heat Transfer and Thermal Engineering; Wen, C., Yan, Y., Eds.; Springer Singapore: Singapore, 2021; pp. 217-223.

11. Milanova, D.; Kumar, R. Heat transfer behavior of silica nanoparticles in pool boiling. J. Heat Transf. 2018, 130, 042401. [CrossRef]

12. Wang, W.; Wu, F.; Yu, Q.; Jin, H. Experimental investigation of titanium tetrachloride in pool boiling heat transfer. Int. J. Heat Mass Transf. 2018, 122, 1308-1312. [CrossRef]

13. Sur, A.; Lu, Y.; Pascente, C.; Ruchhoeft, P.; Liu, D. Pool boiling heat transfer enhancement with electrowetting. Int. J. Heat Mass Transf. 2018, 120, 202-217. [CrossRef]

14. Rainey, K.N.; You, S.M. Pool boiling heat transfer from plain and microporous, square pin-finned surfaces in saturated FC-72. J. Heat Transf. 2000, 122, 509-516. [CrossRef]

15. Parker, J.; El-Genk, M.S. Saturation boiling of HFE-7100 dielectric liquid on copper surfaces with corner pins at different inclinations. J. Enhanc. Heat Transf. 2009, 16, 103-122. [CrossRef]

16. Klein, G.; Westwater, J. Heat transfer from multiple spines to boiling liquids. AIChE J. 1971, 17, 1050-1056. [CrossRef]

17. Zhang, Y.; Zhou, J.; Zhou, W.; Qi, B.; Wei, J. CHF correlation of boiling in FC-72 with micro-pin-fins for electronics cooling. Appl. Therm. Eng. 2018, 138, 494-500. [CrossRef]

18. Hdhiri, N.; Ben-Beya, B.; Lili, T. Effects of internal heat generation or absorption on heat transfer and fluid flow within partially heated square enclosure: Homogeneous fluids and porous media. J. Porous Media. 2015, 18, 415-435. [CrossRef]

19. Hdhiri, N.; Souayeh, B.; Alfannakh, H.; Ben-Beya, B. Natural convection study with internal heat generation on heat transfer and fluid flow within a differentially heated square cavity filled with different working fluids and porous media. BioNanoScience 2015, 9, 702-722. [CrossRef]

20. Taylor, J.R. An Introduction to Error Analysis, 2nd ed.; University of Science Book: Sausalito, CA, USA, 1997.

21. Takouna, I.; Dawoud, W.; Meinel, C. Accurate multicore processor power models for power-aware resource management. In Proceedings of the IEEE International Conference on Dependable, Autonomic and Secure Computing 9, Sydney, Australia, 12-14 December 2011.

22. Yong, J.; Kim, M.; Kaviany, M.; Young, S. Bubble nucleation in microchannel flow boiling using single artificial cavity. Int. J. Heat Mass Transf. 2011, 54, 5139-5148. 